Monatsschrift f. Geburtshülfe u. Gynäkologie 1928;80:242

\title{
Luigi Mangiagalli †
}

In Mailand ist anfangs dieses Monats (Juli 1928) einer cler einfluß-reichsten Führer der modernen Frauenheilkunde in Italien gestorben! Mangiagalli war ein typiseher Norditaliener: hochintelligent, vollei Ideen, deren Verwirklichung er mit unermüdlieher Kraft durchsetzte! Ein Schüler von Fibone-Tnr'm tmd Calderini-Bologna besuchte er vor seiner S $\theta$ ßhaftmachung Paris mid Berlin. Er machte mir in seineu mehrwöchigen Arbeiten an meiner Seite den Eindruck eines Mamies von ungewöhnlichem Wissen und unentwegtem Können.

Früh $\Lambda$ vnrde il $\pi$ n die Entwicklung der gynäkologischen Klinik in Mailand anvertraiit: er hat sie zu einem vveithin wirkenden Zentrum ent-wick $\theta 1 t$ ! Er hat die Klinik, der er freigebig aus seinen eigenen Mitteln aufhalf, liis vor wenigen Jahren geführt und ausgestaltet.

Seine unerschöpfliohe Tatkraft ließ ilm, den glühenden Patrioten, auch in Stadt mid Staat $1>$ edeutungsvolle Aufgaben übernehmen. Er war einer der ersten faszistischen Senatoren in Rom und Biirgermeister von Mailand, das er in seiner stolzaufstrebenden Entwicklung im Wettstreit mit Rom führte!

Mangiagalli war ein lebhafter Mitarbeiter bei dem Streben nach internationalem

Zusammenschluß unseres Faches. Mit Jacobs und dem UiiterzeichiiӨten wurde er zum

Treuhänder des Kapitals der internationalen gynäkologischen Gesellsehaft gewählt. Nach dem vorzeitigen Tod von Jacobs habe ich in Übereinstimmung mit Mangiagalli diesen Schatz, der in einer Brüsseler Bank ruht, der Belgischen gynälcologischen Gesellsehaft anvertraut.

Mangiagallis wissenschaftlichen Leistungen liegegnen wir aid' alien (1/8bietes unseres Faches: er war seinerzeit auch Mitarbeiter dieser Monats-schrift. Bewunderungswürdig polyglott, ein sehr gewandter Redner, war er auf alien Gebieten von Wissenschaft und Kunst orientiert.

Ala,ngiagallis Name wird in Mailand durch seine Stiftungen festgehalten bleiben. Mit seinen zahlreichen Scliülern und Freunden bewahre ich ihm ein treues Andenken! A. Martin. 